\title{
World Malaria Day 2014: Invest in the future. Defeat malaria
}

\author{
Hoda Atta ${ }^{7}$ and John Reeder ${ }^{2}$
}

Every year, World Malaria Day (held on 25 April) provides an opportunity to review regional and national efforts to reduce the malaria burden, and to reiterate political commitment for the control and elimination of this mosquito-borne disease. In the WHO Eastern Mediterranean Region, almost 300 million people are at risk of malaria, and transmission occurs in eight countries. In 2012, there were an estimated 13 million malaria cases and 18000 deaths [1].

Two countries - Sudan and Pakistan - account for more than $80 \%$ of all estimated cases, while Afghanistan, Djibouti, Somalia and Yemen also have high transmission rates. In the Islamic Republic of Iran and Saudi Arabia, malaria transmission is spatially limited, and in Iraq the last two locally transmitted cases reported were in 2008. In Afghanistan, Islamic Republic of Iran and Pakistan, most malaria cases are due to Plasmodium vivax, while in all other countries P. falciparum is the dominant parasite species. P. falciparum is responsible for the large majority of severe and deadly forms of malaria.

Since 2000, all malaria-endemic countries in the Region have scaled up malaria control and elimination activities and most have reduced their disease burden, and the frequency and intensity of malaria epidemics. This has been driven by expanded funding for malaria control, and by a strengthening of malaria programmes at the national level. The expansion of efforts has resulted in improved access to WHO-recommended artemisinin-based combination therapies, or ACTs, which are the most effective treatment for uncomplicated malaria [2] and a scale up of vector control tools, such as long-lasting insecticidal nets and indoor residual spraying [1].

Changes in climate and ecology [3], urbanization and improved access to health care have also contributed to progress and improved outcomes. During this period, the epidemiology of malaria has changed considerably. In countries with Afrotropical malaria (Djibouti, Somalia, Sudan, Yemen), malaria transmission was substantially reduced, with fewer people living in areas with moderate to high transmission $[4,5]$. However, surveillance systems - across most of the endemic countries of the Region - do not capture all cases so we cannot accurately measure progress in all countries [1].

There have been tangible results in some countries with low transmission rates. Egypt, Oman, Iraq and the Syrian Arab Republic have eliminated the disease, although a few local cases following importation in areas of high receptivity may occur. The Islamic Republic of Iran and Saudi Arabia have limited malaria transmission to a few districts along the borders with Pakistan and Yemen respectively. The United Arab Emirates and Morocco were certified free of malaria in 2007 and 2010 , respectively $[6,7]$. The situation in Afghanistan is also encouraging; the country is projected to reduce its case incidence by more than $75 \%$ by 2015 , and is on track to cut local falciparum cases to zero [1].

Progress has been somewhat slower in countries with higher transmission rates. Pakistan has not managed to mount a sufficiently robust response, partly because its decentralised malaria programmes do not have adequate capacities and resources. The country's response was also complicated by the 2010 floods, in which one-fifth of Pakistan's territory came under water, affecting over 20 million people. The slow progress in Pakistan has a negative impact on other countries' malaria efforts: the movement of populations from endemic areas, mostly workers seeking new opportunities, is leading to outbreaks in malaria-free countries in the Arabian Peninsula and also in areas outside the Eastern Mediterranean Region $[1,8]$.

Gains in the fight against malaria are fragile in all regions of the world. If interventions are not sustained - or are abandoned due to conflict, humanitarian disasters, or a lack of political commitment - resurgences are certain to occur.

Cautionary tales are abundant: in Afghanistan, the 1970s war led to major epidemics, erasing the gains of the country's eradication programme. This resurgence contributed to a serious deterioration of the malaria situation in neighbouring Pakistan, Iran and Tajikistan. Or take the case of Iraq. Iraq managed to reduce its vivax cases below 4000 per year by the end of the 1980s, but in the wake of the Gulf war, the number of cases shot up to 100000 . In the 1990s, the termination of the 10-year Blue Nile Health Project in Gezira, Sudan, triggered a major malaria resurgence, with case incidence rates 
soaring and exceeding those at the start of the project [9].

The future of malaria control and elimination depends greatly on the larger enabling environment for disease control (including the absence of conflict and humanitarian emergencies), the degree of political commitment, the availability of funding, and the structure and capacity of national malaria control programmes. Given the political unrest in many parts of the Region, such as the ongoing armed conflict in the Syrian Arab Republic, there is a real threat that malaria will resurge and spread to areas where the disease had been brought under the control. With the lack of epidemiological and entomological surveillance in the Syrian Arab Republic and the movement of refugees, malaria transmission may spread to neighbouring areas of Turkey and Iraq.

To move towards elimination and fulfil the regional commitment [10], malaria programmes need to have strong capacity at all levels, together with strong district information and diagnostic systems. Programmes need to strengthen diagnostic testing, quality-assured treatment and surveillance, in line with WHO's T3: Test. Treat. Track initiative [11]. Improvement of cross-border and regional collaboration is imperative. Ministries of health need to invest more in operational research, and pay close attention to emerging drug and insecticide resistance. Collaborative efforts should be expanded to facilitate the engagement of sectors outside of health to ensure a genuine multi-sectoral response to the complex challenges posed by malaria.

This is a critical juncture for the global malaria partnerships and for endemic countries in the Eastern Mediterranean Region. The political and funding allocation decisions will determine whether countries can progress towards elimination, or will have to witness and respond to major resurgences and outbreaks. With the support of the Malaria Policy Advisory Committee, WHO will continue to regularly review evidence and update its policy recommendations to help countries reduce their malaria burden, and save more lives.

We have an important opportunity to win this battle and eliminate malaria from this Region. But we must push hard if we want to take this disease over the edge and consign it to history.

\section{Acknowledgements}

We are grateful to Dr Ghasem Zamani of WHO-EMRO for his review and insightful comments which helped enhance the editorial. We thank the National Malaria Programmes in Ministries of Health of EMR countries who provided the malaria data used in the article.

\section{References}

1. World malaria report 2013. Geneva, World Health Organization, 2013 (http://www.who.int/malaria/publications/world_ malaria_report/en/, accessed 20 March 2014).

2. Abdelgader TM et al. Progress towards implementation of ACT malaria case-management in public health facilities in the Republic of Sudan: a cluster-sample survey. BMC Public Health, 2012, 12.

3. McMichael AJ, Woodruff RE, Hales S., Climate change and human health: present and future risks. Lancet, 2006, 367(9513):859-869.

4. Noor $\mathrm{AM}$ et al The changing risk of Plasmodium falciparum malaria infection in Africa: 2000-10: a spatial and temporal analysis of transmission intensity. Lancet, 2014. doi: 10.1016/ S0140-6736(13)62566-0 (Epub ahead of print).

5. Atta H, Zamani G. The progress of Roll Back Malaria in the Eastern Mediterranean Region over the past decade. Eastern Mediterranean Health Journal, 2008, 14(Suppl.):S82-S88.

6. United Arab Emirates certified malaria-free. Weekly Epidemiological Record, 2007, 82(4):30-32.

7. Morocco certified malaria-free. Weekly Epidemiological Record, 2010, 85(24):235-236.
8. Snow RW et al. The malaria transition on the Arabian Peninsula: progress toward a malaria-free region between 1960-2010. Advances in Parasitology, 2013, 82:205-251.

9. Emerging and resurgent diseases in the Eastern Mediterranean Region with special reference to malaria. Technical paper presented at the Forty-fifth Session of the WHO Regional Committee for the Eastern Mediterranean, 1998 (EM RC 45) (http://applications.emro.who.int/docs/em_rc45_9_en.pdf, accessed 20 March 2014).

10. Malaria elimination in the Eastern Mediterranean Region: vision, requirements and strategic outline. Technical discussion paper presented at the Fifty-fifth Session of the WHO Regional Committee for the Eastern Mediterranean, 2008 (EM/RC55) (http://applications.emro.who.int/docs/EM_RC55_tech_ disc_2_en.pdf, accessed 20 March 2014).

11. T3: Test. Treat. Track. Scaling up diagnostic testing, treatment and surveillance. Geneva, World Health Organization, 2012 (http:// www.who.int/malaria/publications/atoz/test_treat_track_ brochure.pdf, accessed 20 March 2014). 